Commentary Campbell \& Woll on Goldin-Meadow \& Brentari [BBS 38, 2016]

\title{
Sign, language and gesture in the brain: Some comments
}

\author{
Ruth Campbell and Bencie Woll
}

Division of Psychology and Language Sciences, University College London, London, WC1E 6BT, England, United Kingdom.

r.campbell@ucl.ac.uk

b.woll@ucl.ac.uk

<C-AB >Abstract: In contrast with two widely held and contradictory views - that sign languages of deaf people are "just gestures," or that sign languages are "just like spoken languages" - the view from sign linguistics and developmental research in cognition presented by Goldin-Meadow \& Brentari (G-M\&B) indicates a more complex picture. We propose that neuroscience research suggests that a similar approach needs to be taken, and offer some examples from research on the brain bases of sign language perception.

\section{$<$ C-Text begins $>$}

Goldin-Meadow and Brentari's article uses evidence from sign linguistics and cognitive development to indicate how sign language processing may be accommodated within cognitive science. We propose that, in addition to perspectives from those disciplines, brain imaging has provided some important leads, as have neuropsychological case studies of patients who sign. In one brain imaging study, for example, deaf native signers were shown signed utterances and brachial gestures (specifically, the traditional tic-tac 
signalling system used by bookies to communicate odds) which could not be interpreted linguistically (MacSweeney et al. 2004). Whereas tic-tac activated posterior and inferior regions of the temporal lobe, signed utterances additionally activated superior temporal and inferior frontal sites, implicating left-hemisphere-dominant perisylvian regions associated with language processing in hearing nonsigners. Further studies also point to a distinction between those manual actions that can be construed as language and those that do not (i.e., signers vs. nonsigners; (Cardin et al. 2015; Newman et al. 2015). Again, these implicate greater activation in left-hemisphere-dominant perisylvian regions for the processing of linguistically structured gestures contrasting with greater activation in posterior/inferior regions for manual gestures which are not linguistically construed. Such studies also lead us to distinguish regions which provide essential sensory input to the language system, and which may be distinct from language processing itself (Corina et al. 2007,1992; Emmorey et al. 2002).

Such sign-focussed studies set up an interesting context for considering co-speech gestures in hearing speakers. Co-speech gestures can be "sign-like" and carry communicative significance. These include emblems such as "thumbs-up," as well as gestures indicating action dynamics and spatial relationships. Behavioral studies show that such gestures modulate the spoken message. Left-hemisphere-dominant perisylvian language regions are specifically activated by co-speech gestures such as these (Özyürek 2014). So, and in contrast with the studies that indicate different processing networks for (sign) language and gesture, these findings emphasize some common processing circuitry for gestures and (heard) speech, and raise issues of interpretation. For example, might 
gestures which sign linguists have appropriated to language analysis be actions which, in people who do not sign, are nevertheless processed by brain circuits associated with language processing? Such considerations drive us to take a more integrative view of language-as-communication.

$<\mathrm{CB}>$ Co-sign gesture. In sign language, face and head actions accompany manual signs and can be construed as "co-sign gestures" (Baker \& Padden 1978). Are such cosign gestures readily dissociated cortically from sign-as-language? The question has not yet been tackled directly, but we offer two insights from our own work. The first is a case-series study of three left-hemisphere-lesioned signers (LH-lesion) and three righthemisphere-lesioned signers (RH-lesion), who were early or native users of British Sign Language (BSL). Their pattern of sparing and impairment led to a specific interpretation of the linguistic status of an utterance (Atkinson et al. 2004).

$<\mathrm{CB}>$ Is negation in sign syntactic? In BSL, as in many other sign languages, headshake can indicate negation of a manually expressed statement, with no accompanying manual marker of negation. We hypothesised that if this is syntactically processed, a headshake accompanying a manual expression should not be interpreted accurately in the LH-lesioned patients, in line with their other linguistic deficits. By contrast, if negation is managed as a prosodic feature, then accuracy may not be predicted by site of lesion, or RH lesions may adversely affect the perception of headshake negation. 
In contrast to their many other language perception deficits, LH-lesioned patients were accurate at distinguishing video clips of signed negative (marked with headshakeonly) utterances. RH-lesioned patients were unable to identify headshake-only negation utterances - although all of their other (manual) sign-language-processing skills were unimpaired. These findings suggest that headshake negation is not processed syntactically - at the very least, that it is not readily accommodated by left hemisphere language processing hitched to a damaged right hemisphere. In this way, neuropsychological investigations may constrain and help develop conceptualisations of those processes which may be construed as "core linguistic" (which, nevertheless, make use of some gestures) and others which may function in rather different ways, with greater reliance on right hemisphere processes.

\section{$<\mathrm{CB}>$ Mouth actions can be more or less linguistic in sign language. Using}

functional magnetic resonance imaging (fMRI), we investigated facial actions accompanying the presentation of lexical manual signs in native deaf users of BSL (Capek et al. 2008). One type of facial action, where mouth actions disambiguate sign homonyms (in BSL, the signs UNCLE and BATTERY have the same manual expression but different mouth actions) has "lexical" import. This type of display generated activation in the same LH-dominant perisylvian regions as manual signs which had no accompanying face action. However, a different type of face action was also investigated. Here, the facial action mimics the dynamics of the manual action ("echo-phonology"). For example, the BSL sign SHUT is a manual gesture of the hands coming together, accompanied by mouth closure. This may not be obligatory for lexical interpretation. In 
contrast to the "disambiguating mouth" signs, the "echo phonology" signs showed less activation in LH perisylvian regions and more activation, bilaterally, in posterior and inferior regions associated with the analysis of visual, nonlinguistic signals (Capek et al. 2008).

While these findings can be interpreted in other ways (Capek et al. 2009, 2010), they suggest that conceptual processes underlying linguistic processing can be expressed and interpreted through means other than speech/manual sign and that these processes leave their mark in the brain of the language user. Questions remain about how gestural elements interact with linguistic elements within the manual component of sign language (see Cormier et al. 2013 on pointing gestures in BSL). It will be interesting to explore gesture more systematically in relation to sign language using brain imaging techniques alongside linguistic and cognitive explorations which, as the target article shows, now offer powerful models of cognitive and linguistic function.

$<\mathrm{C}$-Text ends $>$

[COMP: DO NOT SET REFERENCES FROM HERE; USE CONSOLIDATED REFERENCES FILE]

$<$ RFT $>$ References [Ruth Campbell and Bencie Woll] [RC]

$<$ refs $>$

Atkinson, J., Campbell, R., Marshall, J., Thacker, A. \& Woll, B. (2004) Understanding "not": Neuropsychological dissociations between hand and head markers of negation in BSL. Neuropsychologia 42(2):214-29. [RC] 
Baker, C. \& Padden, C. (1978) Focussing on the non-manual components of ASL. In: Understanding language through sign language research, ed. P. Siple, pp. 27-57. Academic Press. [RC]

Capek, C. M., Grossi, G., Newman, A. J., McBurney, S. L., Corina, D., Roeder, B. \& Neville, H. J. (2009) Brain systems mediating semantic and syntactic processing in deaf native signers: Biological invariance and modality specificity. Proc Natl Acad Sci U S A 106(21):8784-89. [RC]

Capek, C. M., Waters, D., Woll, B., MacSweeney, M., Brammer, M. J., McGuire, P. K. , David,A.S. \& Campbell, R. (2008) Hand and mouth: Cortical correlates of lexical processing in British Sign Language and speechreading English. J Cogn Neurosci 20(7):1220-34. [RC]

Capek, C. M., Woll, B., MacSweeney, M., Waters, D., McGuire, P. K., David, A. S., \& Campbell, R. (2010) Superior temporal activation as a function of linguistic knowledge: Insights from deaf native signers who speechread. Brain Lang 112(2):129-34. [RC]

Cardin, V., Orfanidou, E., Kästner, L., Rönnberg, J., Woll, B., Capek, C. M. \& Rudner, M. (2015) Monitoring different phonological parameters of sign language engages the same cortical language network but distinctive perceptual ones. Journal of Cognitive Neuroscience 1:20-40. [RC]

Corina, D., Chiu, Y. S., Knapp, H., Greenwald, R., San Jose-Robertson, L. \& Braun, A. (2007) Neural correlates of human action observation in hearing and deaf subjects. Brain Res 1152:111-29. [RC] 
Corina, D. P., Poizner, H., Bellugi, U., Feinberg, T., Dowd, D. \& O’Grady-Batch, L. (1992) Dissociation between linguistic and nonlinguistic gestural systems: A case for compositionality. Brain Lang 43(3):414-47. [RC]

Cormier, K., Schembri, A. \& Woll, B. (2013) Pronouns and pointing in sign languages. Lingua 137:230-47. [RC]

Emmorey, K., Damasio, H., McCullough, S., Grabowski, T., Ponto, L. L., Hichwa, R. D. \& Bellugi,U. (2002) Neural systems underlying spatial language in American Sign Language. Neuroimage 17(2):812-24. [RC]

MacSweeney, M., Campbell, R., Woll, B., Giampietro, V., David, A. S., McGuire, P. K. , Calvert,G.A. \& Brammer M.J. (2004) Dissociating linguistic and nonlinguistic gestural communication in the brain. Neuroimage 22(4):1605-18. [RC]

Newman, A. J., Supalla, T., Fernandez, N., Newport, E. L. \& Bavelier, D. (2015) Neural systems supporting linguistic structure, linguistic experience, and symbolic communication in sign language and gesture. Proc Natl Acad Sci U S A 112(37):11684-89. [RC]

Özyürek, A. (2014) Hearing and seeing meaning in speech and gesture: Insights from brain and behaviour. Philos Trans R Soc Lond B Biol Sci 369(1651):20130296. [RC]

$<$ refs end $>$ 